\title{
Erratum to: Cracks coalescence mechanism and cracks propagation paths in rock-like specimens containing pre-existing random cracks under compression
}

\author{
Hadi Haeri ${ }^{1}$, Kourosh Shahriar ${ }^{2}$, Mohammad Fatehi Marji ${ }^{3}$, Parviz Moarefvand ${ }^{2}$
}

1. Department of Mining Engineering, Science and Research Branch, Islamic Azad University, Tehran, Iran;

2. Department of Mining and Metallurgical Engineering, Amirkabir University of Technology, Tehran, Iran;

3. Mine Exploitation Engineering Department, Faculty of Mining and Metallurgy, Institution of Engineering, Yazd University, Yazd, Iran

(C) Central South University Press and Springer-Verlag Berlin Heidelberg 2014

Erratum to: J. Cent. South Univ. (2014) 21: 2404-2414

DOI: $10.1007 / \mathrm{s} 11771-014-2194-\mathrm{y}$

The original version of this article unfortunately contained a mistake. The E-mail addresses of the corresponding author are incorrect. The corrected information of the corresponding author is given below.

Corresponding author: Hadi Haeri, PhD Candidate; E-mail: haerihadi@gmail.com, hadihaeri@ymail.com

The online version of the original article can be found at http://dx.doi.org/10.1007/s11771-014-2194-y 